\title{
EARTHQUAKE DESIGN AND PERFORMANCE OF STEEL STRUCTURES
}

\author{
H Krawinkler ${ }^{1}$
}

This paper was presented as one of the keynote addresses at the Pacific Conference on Earthquake Engineering, PCEE 95, Melbourne, November 1995.

\begin{abstract}
SUMMARY
The 1994 Northridge earthquake has shown that steel structures may experience local failure modes that have not been observed in earlier earthquakes. The attention of the public and the engineering community has been drawn particularly to frequently observed fractures at welded beam-to-column connections. The local failures have raised design and research issues that have become the focus of extensive professional and research efforts directed towards improvement of the performance of steel structures in future earthquakes.
\end{abstract}

\section{INTRODUCTION}

This paper summarizes the performance of steel structures in the 1994 Northridge, California, earthquake and addresses issues raised by deficiencies in the performance. Considering the severity of the ground shaking and the large number of steel structures existing in the affected area, the Northridge earthquake can be viewed as the first severe seismic field test of modern steel structures. The summary observation is that significant problems were noted but no structural collapses have occurred. The attention of the public and the engineering community has focused primarily on fractures in welded beamto-column connections in moment resisting frames, which were observed in many buildings from 1 to 26 stories high. Because of the large impact of these local failures, little attention has been paid to the behavior of braced frame structures.

Damage observations are summarized for both braced and moment resisting frame (MRF) systems. The damage observations are followed by a discussion of design and research issues raised by the observed fractures in and around welds of the standard beam-to-column connection that is used in a great majority of the MRF structures built after 1960 in highly seismic regions of the United States. The fractures have been attributed to many sources, including design and material issues as well as a variety of welding problems. To mitigate the immediate and long range effects of these fractures on seismic safety and design/fabrication practice, efforts are underway to improve the expected performance of MRF structures with welded beam-to-column connections through modifications of seismic code requirements, tighter material specifications, better control of welding procedures and inspection, and development of connection details that will prevent the occurrence of high stresses in critical regions at weldments. The knowledge needed to implement improved design, detailing, and fabrication

1 Stanford University, Stanford, California, U.S.A. procedures is being acquired through focused research and development efforts. The main components of these efforts, which are in progress, are as follows:

- identification of problems that may have contributed to fractures in welded connections,

- assessment of the expected seismic performance of damaged and undamaged existing steel MRF structures,

- development of reliable methods for repairing damaged MRF structures and upgrading undamaged ones whose expected seismic performance may be inadequate, and

- development of procedures for designing, fabricating, and erecting economical new steel MRF structures with reliable seismic performance characteristics.

Much of this paper is devoted to a discussion of some of these issues.

\section{PERFORMANCE OF STEEL STRUCTURES IN THE 1994 NORTHRIDGE EARTHQUAKE}

The January 17, 1994, Northridge earthquake was the first relatively large earthquake to occur directly below a large metropolitan area in the U.S. in more than 60 years. The direct damage caused by the earthquake is estimated to be in the order of 20 billions U.S. dollars. A significant number of complete or partial collapses have occurred, particularly of wooden apartment buildings, precast concrete parking garages, older cast-in-place reinforced concrete buildings, and reinforced concrete freeway overpasses. The damaging effects of the earthquake have to be understood in the context of the large ground motions that have been recorded over a relatively large area. Many of the spectra of motions recorded within $20 \mathrm{~km}$ of the epicenter exceed presently employed design spectra by a large margin over a wide period range. Structural damage appears to be an acceptable consequence for such motions according to present code intent. 
The question is what constitutes acceptable damage and what must be considered unacceptable damage. The following interpretation is used here. Acceptable damage is damage that conforms to design intent and could have been foreseen based on the philosophy contained explicitly or implicitly in seismic codes (e.g., plastic hinging as well as limited local and lateral torsional buckling in beams, or global buckling of bracing members). Unforeseen damage that has little or no consequence on structural performance may be placed in the same category. Unacceptable damage is unforeseen damage that has, or may have, severe consequences on seismic performance. In the following discussion such damage is denoted as failure since it fails to meet the design intent.

There is no doubt that partial collapses must be considered failures. It is a matter of interpretation to what extent local failures at the element level, which have not led to partial or complete collapse, should be considered failures. It depends on the severity of consequences, which must be evaluated analytically for cases in which no partial collapse occurred. Since such an evaluation needs to be done on a case-by-case basis and is often subjective, a clear distinction is made here between local and global failures, and a judgment on global failure is made only in cases in which local failures reduced the lateral load resistance clearly by more than one third.

Using these definitions, very few global failures have occurred in steel structures during the Northridge earthquake. The most evident global failure related to steel construction was the collapse of a portion of the perimeter scoreboard assembly at the Anaheim Stadium. A steel braced frame structure in which a great number of base plates fractured may have to be considered a global failure since the base plate fractures reduced the lateral load resistance of the structure by a large percentage. A few of the steel MRF structures in which a great majority of the beamto-column connections fractured also may have to be called global failures. But the great majority of failures observed in steel structures are local failures whose consequences on structural performance need to be evaluated on a case-by-case basis.

This is not to say that local failures of the types summarized next are acceptable. In general they are not, and measures must be taken to prevent such failures in future designs. The later discussed research and development efforts are directed towards the development of such measures.

\section{Performance of Braced Frame Structures}

\section{Bracing Members and Brace Connections}

Most braced frames performed as expected in severe earthquakes. Several instances of brace buckling were reported but no case is known in which brace buckling by itself brought the structural system close to failure. There is one case, however, in which brace and brace connection performance had very undesirable consequences that did cause concerns about structural integrity. This is the case of a 4-story office building in which primary lateral load resistance was provided by thinwalled tubular braces in a concentric chevron arrangement. Several of the tubular braces buckled globally, causing severe local buckling with very large local strains as shown in Figure 1. This severe local buckling occurred at three places in a brace; at the two ends close to the gusset plates and in the middle of the brace. Under cyclic load reversals cracks formed at the corners of the tubes where the strains due to local buckling are highest and large residual strains exist due to the

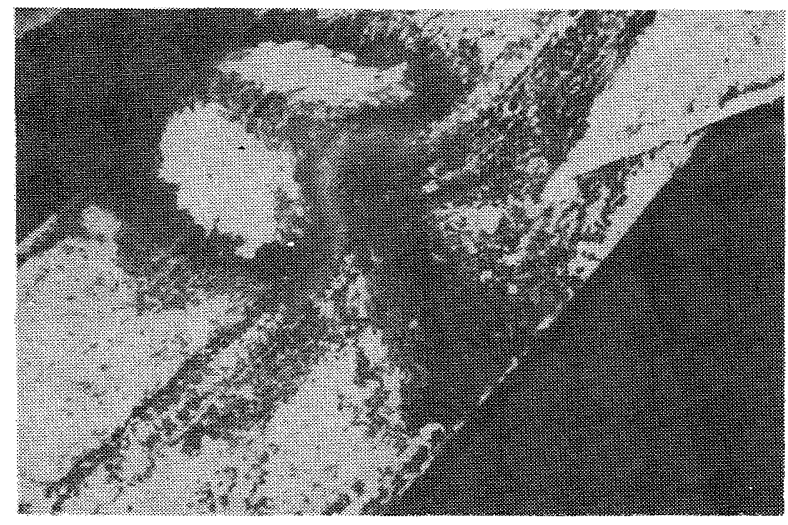

FIGURE 1. Severe local buckling in a tubular brace

cold-forming process. The cracks must have propagated rapidly under load reversals and led to several brace fractures. Some of the braces fractured in the middle and others fractured near the gusset plate. This type of failure has been observed in several experimental studies (e.g., $[6,9]$ ) and points out the need for strict limitations on the allowable width/thickness ratio of walls in tubular sections. The recommendation made in [9] is to limit the width/thickness ratio in tubular braces to a value of 18 .

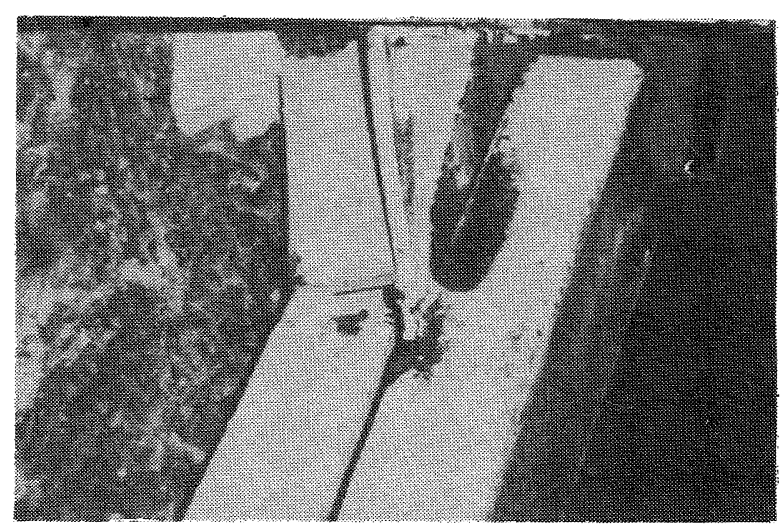

FIGURE 2. Fracture at welded brace connection

In the same structure a second type of failure was observed that had equally severe consequences. The braces were slotted at the ends and fillet welded to gusset plates which in turn were welded to the bottom flange of the beams (in the middle of the chevron). Weld fracture of the type shown in Figure 2 was observed. It is not known to the writer whether this type of fracture occurred because of insufficient fusion or because of insufficient length or size of welds. The latter would be possible without violating the present seismic code, which limits the maximum force that must be transferred through a connection to a certain fraction (usually in the order of $3 / 8$ ) of the force due to the elastic spectral strength demand. This may be inadequate in cases in which the braces are strong and attract high story shear forces. Thus, more effort needs to be devoted to a more accurate determination of the maximum force that can be attracted in a brace and to detailing that assures that this maximum force can be transferred safely through the brace connection. 


\section{Column Base Plates}

Several cases of cracks in welds connecting columns to base plates have been reported. In general, these cracks propagated horizontally along the welds and led to partial separation between a column and the supporting base plate. Such local failures have been observed in other earthquakes and cannot be considered surprises. In one case, however, dramatic vertical fractures were seen in many heavy base plates of slender singlebay $\mathrm{x}$-braced frames that were provided around the perimeter of a 4-story building located not far from the epicenter of the earthquake. A photo of a typical column base connection is shown in Figure 3. The column was welded to the base plate, and on one side a diagonal brace was welded to a gusset plate which in turn was welded to the column web and the base plate. The base plate was connected to a concrete pedestal by means of four long anchor rods. A shear key was welded to the bottom of the base plate, as can be seen below the torch-cut section of the plate.

Many of the $10 \mathrm{~cm}$ thick base plates fractured in a very consistent pattern as shown in Figures 4 and 5. The fracture was usually close to vertical and extended all across the width and through the thickness of the base plate. It occurred always at the side opposite the brace connection and usually several centimeters in from the edge of the column flange. In addition to the base plate fractures, horizontal cracks were usually observed along the welds connecting the two column flanges to the base plate, extending from the edge of the column flanges to or beyond the fracture surface in the base plate (Figure 4).

The following scenario is postulated for these failures. Most of the braced bays were slender (height to width ratio of about 4) and had to support relatively light gravity loads but large seismic inertia forces since bracing was provided only at the perimeter of a large floor area. Since the braces were relatively strong, large story shear forces and therefore large overturning moments were generated. The overturning moments did generate large tensile forces in the columns, which in turn caused significant bending moments in the base plates. The critical spots were the welds at the edges (tips) of the column flanges, where cracks initiated. The cracks propagated horizontally along the column flanges towards the column web, thus increasing the distance between the tensile stress resultant in the column and the anchor rods, which further increased the bending moments in the base plate. The cracks likely turned into the base plate when the horizontal tensile stresses due to plate bending exceeded a certain threshold.

After the base plate fractured, other events happened that led to more damage. Since only part of the base plate was connected to the column, the whole uplift force had to be resisted by the two anchor rods on the side of the diagonal brace. This led to pull-out or yielding of the anchor rods, as was evident in a clear separation noticed between several of the anchor rod nuts and the base plates. The portion of the base plate still connected to the column uplifted and bounced back on the concrete pedestal, causing damage to the pedestal and widening of the crack.

The damage to the pedestal increased further by shear transfer problems. Since the anchor rods became ineffective for shear transfer after fracture of the base plate, most of the shear had to be transferred through the shear key welded to the bottom of the base plate. Figure 3 shows that the concrete around the shear key and around the anchor rods exhibits significant crushing and splitting caused by shear transfer problem and tension in the anchor rods due to uplift.

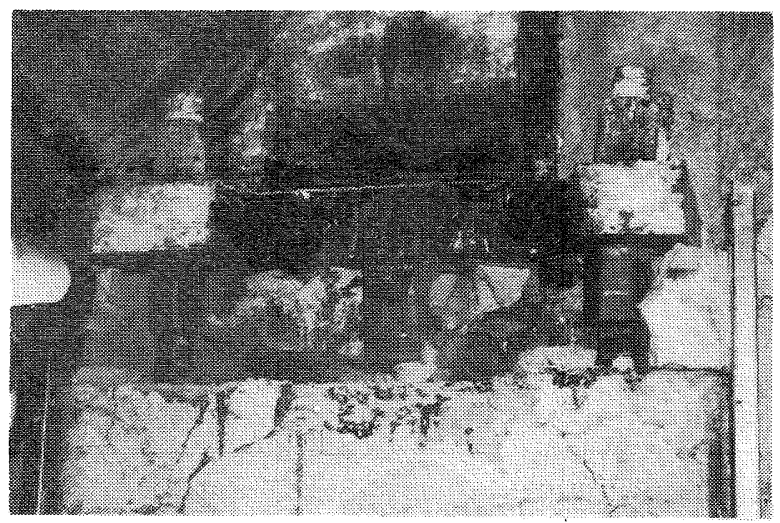

FIGURE 3. Base connection for column and brace

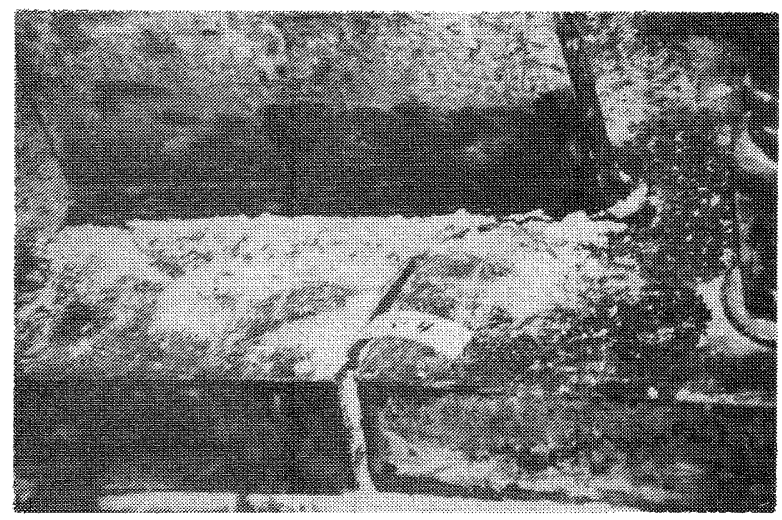

FIGURE 4. Crack propagation in weld and base plate

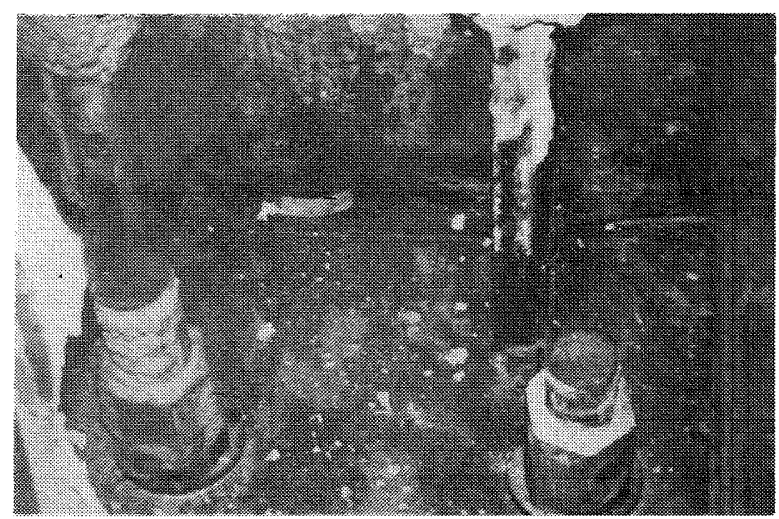

FIGURE 5. Fracture across base plate

The question to be answered is why plates made of apparently ductile steel fractured in such a dramatic fashion. Material studies performed after the earthquake did show that the plate material fulfills the ASTM strength and chemical composition requirements for $\mathrm{A} 36$ steel. The question needs to be answered from the viewpoints of fracture mechanics and welding technology. A crack, once it has formed (in this case as a horizontal crack at the column flange to base plate weld), can easily change direction in conformance with the orientation of 
the principal tensile stress and the fracture mechanics properties of the materials. Significant tensile stresses may have preexisted near the surface of the plate since a relatively thin flange was welded to a thick plate that acted as a heat sink and cooled rapidly compared to the column flange. The rapid cooling may also have caused surface embrittlement in the base plate, which degraded the fracture properties.

\section{Performance of Moment Resisting Frame Structures}

With the exception of one kind of local failure, steel moment resisting frame (MRF) structures performed as expected when subjected to severe ground motions. With the one exception, one can make sound arguments that MRFs performed even better than expected. Based on many analyses performed recently on steel frame structures in the affected area, the conclusion can be drawn that the story drift demands were significant but that inelastic deformation demands were relatively small. The reason is that most MRF structures are much stronger than required by code. Only very few cases are known to the writer in which significant but expected structural damage (large plastic deformations in beams, columns or joint panel zones, or significant local or lateral torsional buckling) was observed. But this positive aspect is overshadowed by the impact made by widely observed connection failures, which have become the main story of the Northridge earthquake. The remainder of this paper focuses on these connection failures.

\section{Performance of Welded Beam-to-Column Moment Connections}

Steel MRF structures vary widely in configurations, but since about 1960 they vary little in beam-to-column connection details. The standard way of connecting beams to columns in SMRFs is to provide moment transfer through full penetration butt welds between the beam flanges and column flanges (strong axis connections) or continuity plates (weak axis connections), and to provide shear transfer through the beam web connection. The latter connection consists of a vertical plate, which is shopwelded to the column and to which the beam web is either bolted only or bolted plus partially welded. A sketch of a threeway connection is shown in Figure 6. For economic and other reasons weak axis moment connections (beams framing into the web of the column) are avoided in most recent structures, resulting in configurations in which only two frames in each direction are MRFs and all other frames provide only gravity load transfer through shear connections. The consequence of this practice is that structural redundancy is reduced considerably compared to structures in which most or all connections are moment resisting.

Local failures at beam to column flange welds have been detected in more than one hundred buildings, ranging in height from 1 to 26 stories, and including hospitals and health care facilities, public and private office buildings, cultural facilities, residential buildings, and commercial and industrial structures. A survey report on observed damage has been published by the National Institute for Standards and Technology [11]. Presented here is a summary of the types of failures observed and a description of the reconnaissance process that has led to the discovery of local failures in more than one hundred MRF structures.

Partial or complete fracturing of parts of elements in welded beam-to-column moment connections has been observed. Fracture implies here that plate elements either separated completely or a large crack existed that caused significant deterioration in the load transfer between plate elements.

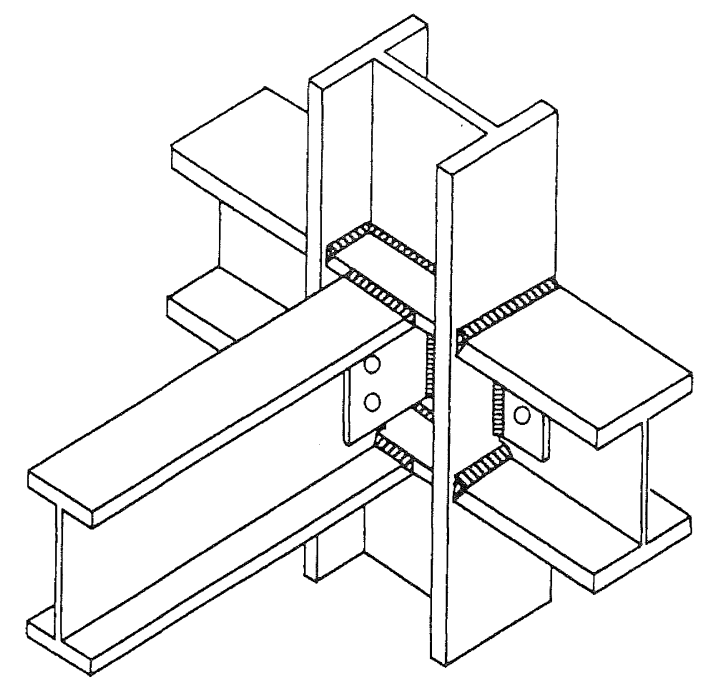

FIGURE 6. Three-way joint with welded connections

Cracks that may have pre-existed or, if caused by the earthquake, did not lead to significant strength deterioration are not considered fractures.

Most common were fractures at weldments connecting the beam flange to the column flange. In the majority of cases the fractures were noted at the beam bottom flange connection; a much smaller but still significant number of fractures has also been identified at the top flange connection. The reasons for the much larger number of bottom flange connection fractures may be that (a) the discontinuity in welding at the web of the beam bottom flange is a source of significant weld imperfection and (b) the floor slab provides composite action with the beam and thus increases the stress level in the bottom flange compared to that in the top flange. Also, some top flange connection fractures may not have been detected since it is much more difficult to inspect the top flange weld due to the presence of the slab.

Failures at flange connections triggered sometimes also failure of the web connection. Several cases were reported of vertical cracking along the web bolt line and/or fracturing of the partial welding that is often provided around the corners of the web shear tab.

Failure modes observed at and around the beam bottom flange weld are illustrated in Figure 7. Very common was the type of fracture shown at the top left of the figure, in which the weld separated cleanly from the column flange. It is quite likely that there are many instances in which the crack did not propagate all the way up the weld-column interface; unfortunately these cracks cannot be detected through visual inspection. In many cases the fracture initiated at the intersection of the backup bar and the column and propagated into the column flange material taking out a piece ("nugget") of the column flange as shown in the second sketch from the left in the top row of the figure Sometimes the crack stopped within the column flange as illustrated in the third sketch from the left. Fracture through the weld material, as shown in the top right sketch, was also observed frequently. The type of fracture illustrated in the lower left of the figure, in which a crack initiated at the toe of the weld and propagated through the heat affected zone in the beam flange, was seen in only a few of the Northridge 


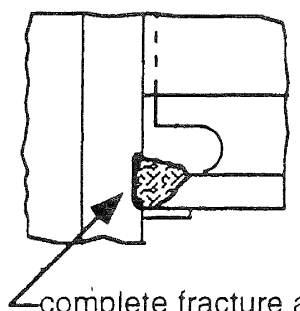

fracture across beam $\rightarrow \angle$ flange at toe of weld

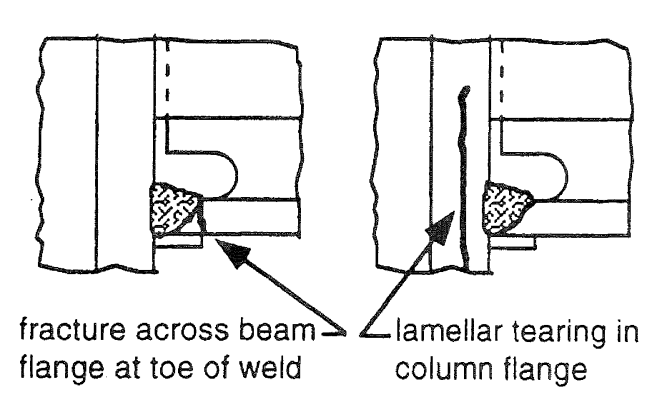

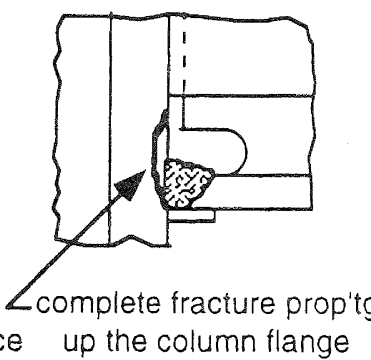

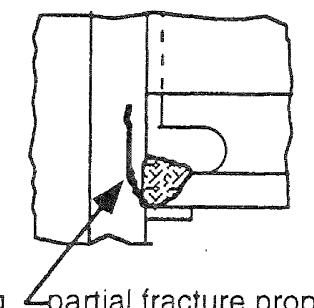
up the column flange

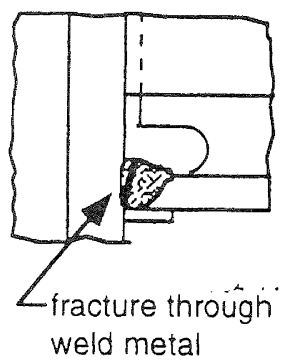

weld metal
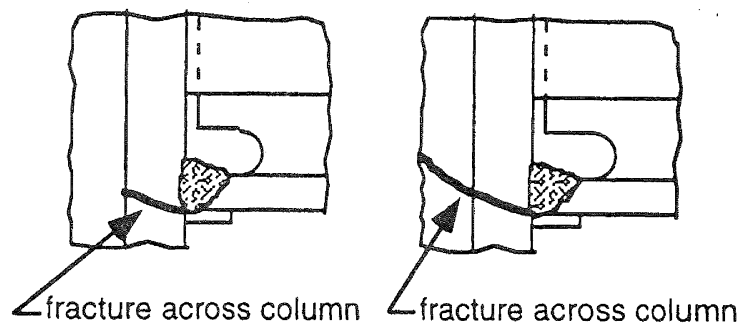

flance (horiz'l or inclined) flange and part of web

FIGURE 7. Fracture modes observed at welded beam bottom

flange to column flange connection

structures but has been observed frequently in experimental studies. Lamellar tearing of the type shown in the second sketch from the left in the bottom row was observed in a box column. The third sketch from the left in the bottom row illustrates frequently observed horizontal or inclined fracturing of the column flange. In some cases the crack extended into the column web as illustrated in the last sketch. At least one case was reported in which horizontal column fracture extended all the way across the column width, causing complete column separation.

An example of a fracture of the type illustrated in the second sketch from the left in the top row of Figure 7 is shown in Figure 8. The surface of such a fracture is shown in Figure 9. The fracture surface extends over the full width of the beam flange and is bounded by the backup bar below the flange, two run-off tabs that acted more like dams on the left and right, and column flange material on the top. Based on the striation markings it is likely that cracking in this case initiated at the two edges of the flange and propagated inward towards the center of the flange. Significant imperfections on the fracture surface can be noted at the two ends, along the interface of the weld and the

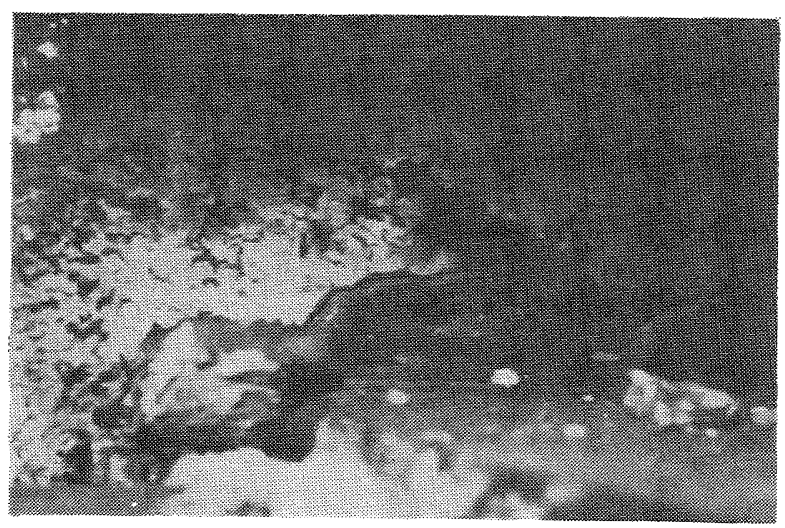

FIGURE 8. Nugget type fracture back-up bar, and in the upper portion where the fracture went through the column material. The imperfections at the interface of the weld and the backup bar have been noted in many fractures, particularly at the center of the weld where welding had to be interrupted because of the presence of the beam web. These imperfections are caused by slag inclusions along the root pass of the weld, which are equivalent to initial cracks.

Examples of fractures extending into the column are shown in Figures 10 and 11 . Figure 10 shows a case in which the column flange fractured horizontally but the crack did not extend into the column web. Figure 11 shows a case in which the column flange fractured at an angle of about 45 degrees and the crack propagated deep into the column web.

The frequency and distribution of failures, and the types of failures, varied widely from building to building. In many buildings only a single type of failure was observed in relatively few connections. At the other extreme, in one building six of the illustrated failure types were observed and about $90 \%$ of the connections in one story had fractures.

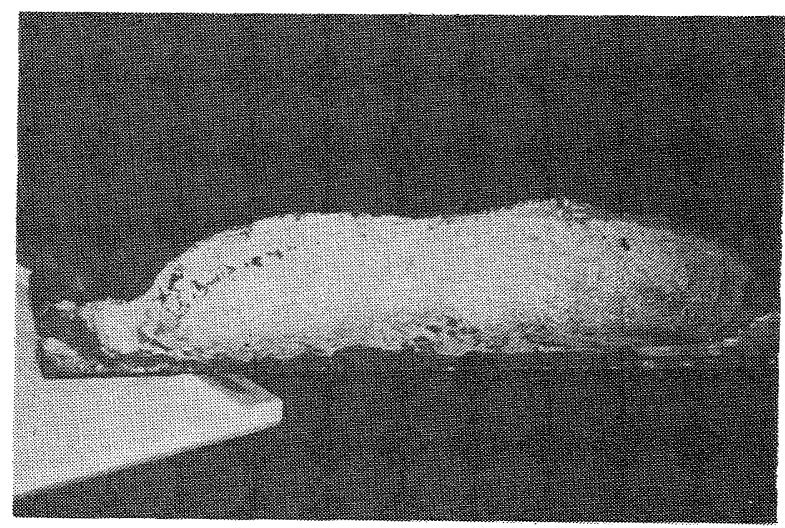

FIGURE 9. Surface of a nugget type fracture 


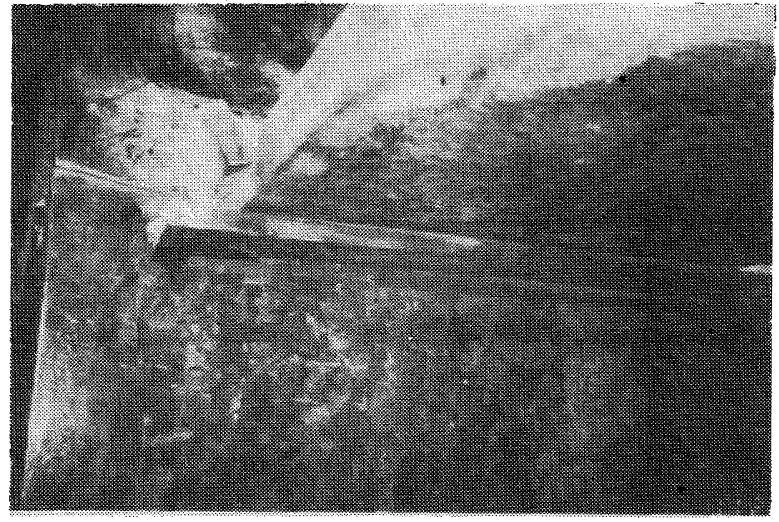

FIGURE 10. Fracture across column flange

The consequences of failure depend on the types and frequency of fractures. A separation between one or both beam flanges and the column implies that the bending resistance of the beam at the column is reduced severely and the hysteresis loops become pinched due to the opening and closing of the cracks under load reversals. As a consequence the energy dissipation capacity of the beam is reduced and more energy needs to be dissipated in other beams that have uncracked connections. Fractures across the column are believed to be even more detrimental since the integrity of the columns is critical to the stability of the structural system. It should be emphasized that in only one case known to the writer was the stability of the building threatened under gravity loads following the main shock.

It must be stressed that connection damage is difficult to find and that a thorough inspection of steel MRF buildings is very time consuming and expensive. In most buildings the structural steel is hidden by architectural finishing materials and fire proofing material. A walk-through visual inspection is useless unless significant nonstructural damage provides hints of potential problems. A visual inspection will miss many fractures and large cracks even after removal of finishing and fire proofing materials. Nondestructive testing (magnetic particle, liquid penetrant, ultrasonic, and/or radiographic testing) is needed to complement visual inspection.

These are the reasons why it took several weeks before the majority of the problems were found. In most cases the local failures did not result in sufficiently large overall deformations (interstory drift) to cause severe and clearly visible damage to nonstructural elements. When nonstructural damage was observed it was attributed to expected inelastic deformations in steel elements. For this reason most of the fractures at connections were not discovered in the initial inspections, and buildings were green-tagged (safe for occupancy) and allowed to function in a normal manner.

Problems at connections were first noted in some buildings that were under construction at the time of the earthquake, and hence the steel was exposed to visual inspection. With time, more and more problems were discovered; some of them accidentally, some because of secondary problems triggered by the local failures, and some because of concerns about large permanent story drifts. In one case, persistent complaints by occupants about a malfunctioning elevator led to the discovery that the building was out of plumb and leaning to the north. In another

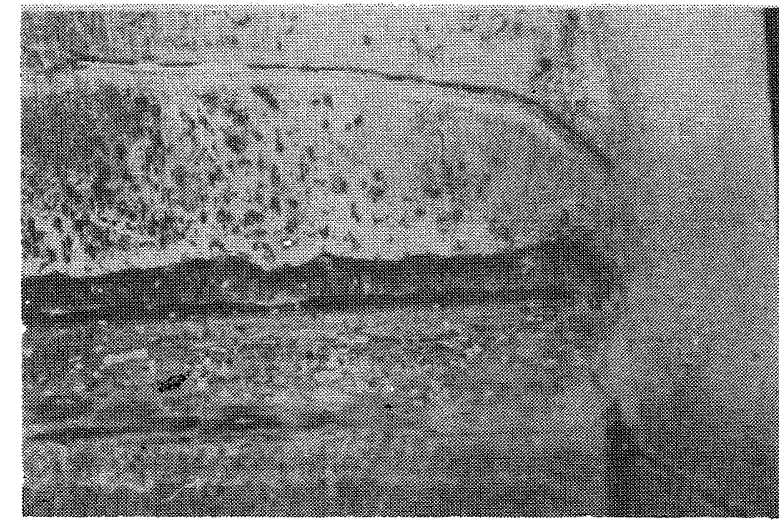

FIGURE 11. Fracture extending into column web

case, loose architectural panels with deformed connectors on the exterior of the building led to a more careful examination of the structure.

The following account of the discovery of weld fractures in a 4story MRF building tells a fitting tale of accidental discovery of major structural problems. The building exhibited severe nonstructural damage and had a permanent drift of less than one inch in the first story. It was thoroughly investigated by experienced engineers but no signs of unusual structural damage were found and the story drift was attributed to yielding in beams and/or columns. The engineering assessment was that the building could be reoccupied after clean-up, and the recommendation was made to pull the structure back in order to reduce or eliminate the permanent drift. By sheer coincidence a crack was detected in the fire-proofing material. The fireproofing material was removed, and a fracture was discovered at the beam bottom flange to column flange connection. To assure that there were no additional problems, the fire-proofing material was removed from adjacent joints, and by the time the process was completed it was discovered that about $90 \%$ of the connections at the top the first story had fractures at or adjacent to the flange welds.

These findings triggered a more thorough inspection of steel structures, most of which were occupied. By late 1994 more than a hundred steel buildings have been identified as having experienced local failures at the welded beam-to-column connections. Many of these buildings have been repaired and in some cases reinforced at a very high cost. It is estimated that there are in the order of 300 more steel MRF structures in the earthquake affected area that still need to be inspected, and it likely that the number of damaged buildings will increase considerably.

\section{POTENTIAL SOURCES OF PROBLEMS IN WELDED MOMENT CONNECTIONS}

Beam-to-column connections in MRFs in highly seismic regions have to fulfill two specific functions. They have to prevent large relative rotations between beams and columns in order to limit story drifts to acceptable values, and they have to transfer safely the maximum moment that possibly can develop in the beam framing into the column. The first function calls for rigidity, a requirement that is fulfilled by connections in which the beam flanges are welded directly to the column. The second 
function is associated with a multitude of potential problems, particularly for the type of connection illustrated in Figure 6.

The maximum beam moment that possibly can develop in the beam framing into the column depends on a great number of parameters, is difficult to evaluate, and is presently not considered explicitly in the design of the connection. In engineering calculations it is usually assumed to equal the plastic bending strength of the beam, computed as $Z F_{y}$, where $Z$ is the plastic section modulus of the beam section and $F_{y}$ is the nominal yield strength of the beam material. The actual maximum moment may be more than twice as large, as will be shown later. At the other extreme, the maximum moment that can be developed in the beam may be a fraction of the plastic bending strength if either the shear strength of the joint panel zone or the bending strength of the column limit the moment transfer from the beam to the joint. There are indications that connections fractured in cases in which the stress level in the beam was clearly below yielding but the joint panel zone yielded and distorted in shear. Considering these variations in maximum beam moments and many other issues related to detailing and welding, it appears justified to worry about the performance of connections in which total reliance is placed in the ability of one full-penetration weld to assure proper load transfer and structural integrity.

Now, one and a half years after the Northridge earthquake and after many experimental and analytical studies, there is one clear conclusion that can be drawn on the welded connection problem: the problem is not a simple one and no single factor can be made fully responsible for it; many factors may have contributed to connection failures. Structural design, material, and welding issues may have to share responsibility. The following enumeration of possible sources of problems is likely incomplete.

\section{Design Issues}

- In most steel MRF structures built recently in the U.S. only few of the frames (usually two in each direction) are made moment resisting. Few frames have to resist all lateral loads, resulting in large member sizes. The beam sizes often have to be increased further because of drift limitations. Large beam sizes implies large welds, which are more prone to fractures than small welds. Adherence to the weak beam concept requires often an additional increase in column sizes. Heavy columns with thick flanges have inferior throughthickness properties, which in combination with large welds increases the likelihood of cracks and fractures around welds.

- Steel MRF structures in which only few frames are moment resisting have low redundancy. Local failures of few connections will have a much greater effect on structural integrity than in highly redundant frame structures in which significant redistribution of internal forces can take place.

- The relative strength of beams, columns, and panel zone at a joint have a great effect on the distribution of inelastic deformations. If beams are the weak elements, inelastic deformations will be concentrated in plastic hinge regions of the beams and flange connection welds will have to be able to transfer very high forces to the joint. If the columns are the weak elements, high vertical strains will exist on the column side of the connection, which may initiate horizontal cracking across the column flange. If the joint panel zone is the weak element, it will yield in shear before the beams attain their bending strength. Excessive shear yielding of the panel zone will lead to local kinking at the four panel zone corners and to high strains and curvatures in the columns at the locations where beam flanges are connected by welding. This may lead to cracking at the welds [4].

- The evaluation of beam bending strength is based on the yield strength of the material. Cyclic hardening during seismic response may increase this bending strength by $50 \%$ or even more [5]. This increased moment will increase proportionally the stress level at the welded connection.

- The contribution of the floor slab, which is mostly of composite construction, to the stress distribution and strength of the beam at the connection is usually ignored. Under positive loading (compression on top) the slab contribution will raise the neutral axis and increase the tensile stress level at the beam bottom flange.

\section{Material Issues}

- The actual yield strength of steel may be significantly different from the nominal value. According to a recent statistical survey [8], the mean yield strength of A36 steel is about $35 \%$ higher than the nominal value. Using this increase together with the aforementioned cyclic hardening increase of $50 \%$, the maximum beam moment may be in the order of twice the nominal strength or more. It is questionable whether the standard welded connection can transfer this moment since the bending strength at the connection is limited to the moment provided by the tensile strength of the flanges and whatever moment can be transferred through the web connection (if the slab contribution is ignored). In any case, the maximum stress at the beam side of the weld is limited to the tensile strength of the flange material, whose mean value is approximately 1.9 times the nominal yield strength [8]. This is the stress that must be transferred through the weld to the column flange.

- The through-thickness properties (orthogonal to the rolling direction) of steel are inferior to those in the rolling direction. The thicker the column flange the more inferior they become. Considering that in the rolling direction the mean tensile strength of A572 steel, which is most commonly used for columns, is only about $10 \%$ higher than the mean tensile strength of A36 steel, there are possibilities of fracture on the column side of welds even without the presence of stress concentrations or pre-existing imperfections or cracks.

\section{Welding Issues}

If all welding is done by well qualified welders according to clearly spelled out and conservatively interpreted welding specifications [1], with approved welding materials and processes, and with proper care to minimize residual welding stresses, and if welds are thoroughly inspected and tested by well qualified NDT technicians, and testing and rejection procedures are rigorously enforced, then welding issues should not be critical to the performance of welded beam-to-column connections. There is no doubt that improvements are needed in many of the processes and procedures related to welding. This will require education of structural engineers on welding issues, and collaboration of welding engineers, technicians, and inspectors in communicating knowledge, providing a high quality product, and enforcing rigorous procedures. 
It is clear that the quality of the welds, and therefore the performance of the w'lded beam-to-column connections, is highly sensitive to the processes and procedures implemented. It must be emphasized that in steel structures an inadequate weld is often more critical than an inadequately sized member. An inadequate member may yield in tension or bending and will deteriorate in compression, but an inadequate weld may fracture and will lead to a sudden and complete loss of resistance.

Only two issues are addressed here since they were noted in many instances related and also unrelated to connection failures during the Northridge earthquake.

- Slag inclusions at column-weld interface. A thorough inspection was performed on a multi-story steel building far away from the Northridge area. In more than two hundred connections the backup bar below the beam bottom flange weld was removed and the weld was back-gouched wherever slag inclusions were noted. This was the case in a majority of the welds. Many of the slag inclusions were of a size that would have called for rejection per AWS D1.1 if they would have been detected during construction. The inclusions were particularly large in the middle of the weld. This is the place where the weld had to be interrupted because of the presence of the beam web. In some cases the inclusions extended from the bottom of the weld to more than half of the weld thickness. Many of these welds were UT inspected during construction and were found to be satisfactory. The reason is that UT inspection is unreliable behind the backup bar and particularly behind the beam web, and requires expert interpretation. The inspected building is not in the Northridge area, but is has to be expected that similar conditions existed in many of the Northridge steel structures. Slag inclusions are equivalent to initial cracks, which are prone to crack propagation at lower stress levels and may result in fracture.

- Inadequate run-off tabs. In many of the fractured connections it can be assumed that cracking started at the ends of the weld and propagated towards the center (see Fig. 9). This assumption is based on the observation that run-off tabs were turned up in a way that they acted as dams rather than run-off tabs. The likelihood is high that large amounts of slag collects behind these dams. Even though these slag inclusions may be outside the edges of the beam flange, they act as stress risers and are triggers for crack propagation.

These two example problems serve to point out the importance of weld quality and inspection. There is no assurance that welds would remain sound without the presence of these problems, but the problems certainly contributed to early connection fractures.

\section{POTENTIAL SOLUTIONS TO PROBLEMS IN WELDED MOMENT CONNECTIONS}

By now there is consensus that a simple and inexpensive solution to the connection problem does not exist. The problem is multi-faceted, as identified in the Introduction, and its solution must be based on research and professional developments that require the participation of many professionals, including but not limited to structural engineers, experimentalists, analysts, reliability experts, metallurgists, welding engineers, welders, inspectors, and NDT experts.
Research and professional developments on many aspects of the problem are in progress and have led already to many conclusions that can be implemented on an interim basis. Many governmental agencies, professional and industry organizations, and universities are involved in these activities. Several experimental studies are sponsored by the National Science Foundation (NSF), the California Office of Emergency Services (OES), the Federal Emergency Management Agency (FEMA), the National Institute for Standards and Technology (NIST), and the American Institute for Steel Construction (AISC). The joint

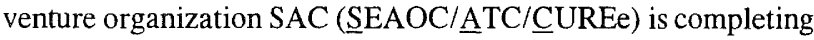
the first phase of an extensive program directed towards the development of guidelines and solutions to the problem. This work is sponsored by FEMA/OES. SAC has published already three design advisories and is in the process of compiling detailed damage statistics, completing a series of state-of-the-art papers on relevant issues, and publishing interim repair and strengthening guidelines [7].

In the following discussion advantage is taken of the knowledge generated in the aforementioned efforts, particularly the SAC effort. But the opinions expressed are those of the author and do not necessarily reflect the majority opinions of others involved in these efforts.

\section{Conclusions Drawn From Experimental Studies}

Many experiments have been performed during the last one and a half years on beam/column subassemblies with various connection configurations. In most cases large size specimens were used, with beams as large as W36x150 and columns as large as $\mathrm{W} 14 \times 450$. Because of constraints imposed by time, cost, and test set-ups, the experiments were performed usually on exterior assemblies consisting of a column with one beam framing into the column at midheight, and without a floor slab. Because of the urgency of the efforts, some of which are still in progress, little has been published so far (June 1995) in the open literature. The SAC design advisories contain some of the experimental results, and a documentation of two of the test series is published in preliminary form $[3,10]$

Many of the experiments started with cyclic loading tests of the standard connection. The tests were continued until local failure occurred. Then the specimens were repaired and the connections were strengthened using a variety of different schemes. Such experiments fulfilled the triple purpose of (1) evaluating the performance of the standard connection, (2) evaluating the adequacy of repair techniques, and (3) providing information on proposed strengthening schemes. In other experiments strengthened connections were used from the beginning. One series of experiments utilized beam/column specimens cut out of a two-story structure that was severely damaged during the Northridge earthquake. In these specimens the column flange was fractured and the crack extended deep into the column web. These specimens were tested first in the damaged configuration, and where then repaired, strengthened, and tested again

The following important observations and conclusions can be made from the experimental studies performed to date:

- None of the tested standard connections achieved a satisfactory performance level, which may be defined as permitting a plastic joint rotation of approximately 0.025 radians without local failure. Fractures at the welds occurred usually at small plastic rotations, in some cases within the first inelastic excursion. 
- The experimental results show that the standard connection cannot be relied upon to develop plastic hinges in beams with adequate rotation capacity.

- After a local fracture occurs, the strength and stiffness in the loading direction causing crack opening deteriorates significantly but some residual strength can be maintained for large rotations. This residual strength varies from $10 \%$ to $40 \%$ of the undamaged capacity. In the loading direction causing crack closure, the original strength can almost be achieved fully. The hysteresis loops change from a stable, symmetric, and fat shape to a pinched shape with much reduced stiffness.

- Even assemblies with fractured column flanges and cracked column webs are capable of developing some residual strength and stiffness.

- In many specimens significant inelastic deformations occurred in the joint panel zone rather than the beam. Even though the beam responded essentially elastically, early fractures did occur. This is an indication that panel zone behavior is an important parameter and that more emphasis needs to be placed on evaluating the effects of panel zone behavior on connection performance.

- In a few specimens local failure was preceded by slippage of bolts in the web connection. The resulting failure was fracture across the column flange.

- Most of the failure modes illustrated in Figure 7 (with the exception of lamellar tearing) were reproduced in the experiments.

- Several of the tested strengthening techniques exhibited very good and reliable performance. Thus, there are alternatives to the standard connection that permit achievement of the previously defined performance goal.

\section{Recommendations on Welding Issues}

Proper welding and weld inspection is a necessary but not sufficient condition for adequate performance of welded connections. The following recommendations are made:

- Experimental evidence has shown that removal of backup bars, which is often an expensive activity, will not improve the performance of a welded connection by much. But it gains much on value if it is followed by a careful inspection for slag inclusions and if areas containing slag inclusions are back-gouched carefully and rewelded. Moreover, it facilitates greatly the interpretation of UT results.

- Great care must be taken in welding through the web cope hole at a beam bottom flange connection, particularly during execution of the root pass. The SAC Interim Guideline No.1 [7] provides detailed recommendations on this issue. Many large imperfections have been detected in welds that stop right at the beam web level.

- Great care must be taken to avoid metallurgical stress risers that may result from arc strikes, tack welds, air-arc gouching, and flame cutting.

- Proper preheating is a critical activity to reduce the possibility of hydrogen embrittlement and to provide a slow cooling rate for the weld and the heat affected zone.
- Hydrogen embrittlement must be minimized through proper pre- and/or postheating and through the use of low hydrogen electrodes.

- Electrode diameter, pass thickness, pass width, travel speed, wire feed rate, and current and voltage must be carefully controlled to produce an adequate weld.

- The welding process must be carefully selected. The costeffective and widely used flux cored self-shielding (FCAWSS) process may not always deliver the best possible product.

- Weld metals should fulfill certain minimum notch toughness requirements. The recommendation made in a SAC workshop is to require a Charpy V-Notch $(\mathrm{CVN})$ value of 20 $\mathrm{ft}-\mathrm{lbs}$ at $30^{\circ} \mathrm{F}$ below the lowest service metal temperature.

- Welding should be performed only by properly certified welders and should be inspected by qualified inspectors. Inspectors should keep comprehensive records of all welders, welding procedures, accepted parts, status of rejected parts, and NDT results.

\section{Alternatives to the Standard Welded Beam-to-Column Connection}

There is general consensus that the presently used standard connection cannot provide adequate force transfer with sufficient reliability. Thus, alternatives to the standard connection need to be developed. Many alternatives have been proposed and several have been tested and were found to provide good force transfer.

The general concept is to move the plastic hinge region in the beam away from the connection and control the stress level at the beam flange welds. This stress level can be evaluated by computing the bending capacity at the plastic hinge location and, knowing this moment value, computing the maximum moment at the connection by statics. It was previously stated that the bending capacity may be twice as high as that computed from nominal properties. The value recommended most widely at this time is a factor of 1.7. The author believes that this value is low if the plastic rotation demand on the beam is high and full cyclic hardening is mobilized.

The four most widely advocated alternatives are illustrated in Figure 12. All of them have undergone limited testing that has shown good performance.

The bottom haunch connection shown at the top left of Figure 12 is very attractive in concept but poses difficulties in welding. The advantage is that it provides a smooth transfer of bottom flange forces to two welds spaced a distance apart. This reduces the stress level at the bottom welds and provides redundancy. It also reduces the stress level at the top flange weld, but to a much smaller degree. Great difficulties exist in welding the web of the haunch section to the bottom flange of the beam because of access problems. These problems are reduced if the slope of the haunch is increased. However, a steep slope (in the order of 45 degrees) is detrimental to the load path and will require much additional depth if the beam plastic hinge is to be moved clearly away from the connection. The vertical stiffener at the end of the haunch is needed to prevent beam flange distortion that may lead to stress concentrations at the center of the weld connecting the haunch flange to the beam flange. 

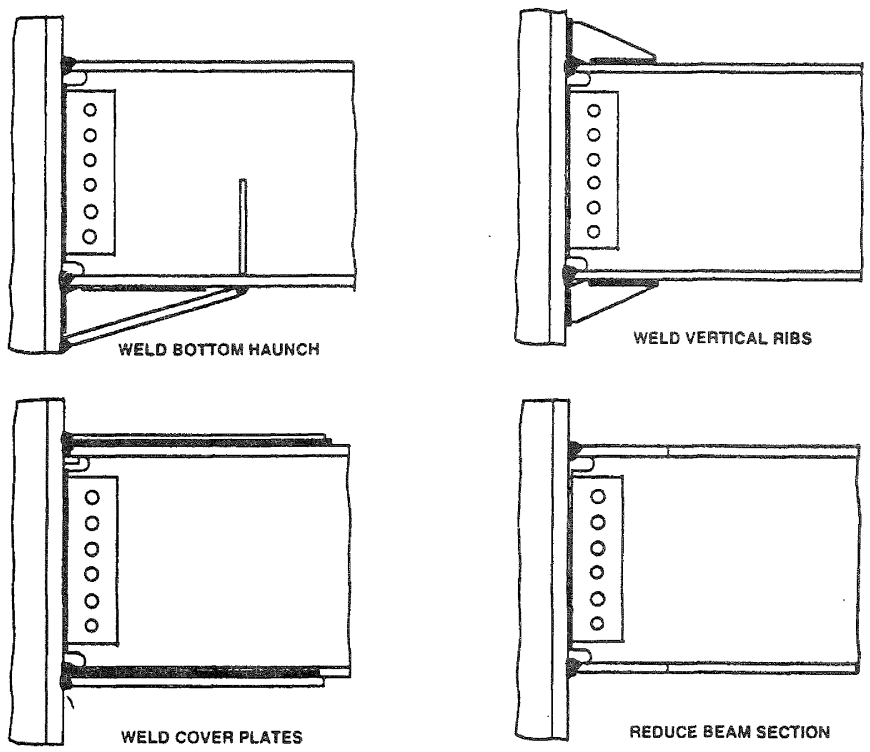

FIGURE 12. Widely advocated alternatives to standard welded connection

There are alternative haunch configurations that deserve consideration. A straight $T$ section could be used rather than a tapered $\mathrm{T}$. In this case the force transfer from the beam bottom flange to the haunch would take place through the weld connecting the web of the $T$ to the beam bottom flange. There are no access problems in making this weld. Alternatively the haunch could consist of a shallow structural shape whose top flange is fillet welded to the bottom flange of the beam. Such a shallow haunch (in the order of $15 \mathrm{~cm}$ ) could also be provided at the beam top flange without intruding into the floor space.

Vertical ribs, as illustrated in the top right sketch of Figure 12, have been used in several repairs of damaged Northridge structures. Limited testing with two ribs welded at the third points of the beam flange has shown satisfactory performance. However, these tests were performed on specimens with very thick column flanges, and it remains to be seen whether stress concentrations, which have to be expected in columns with thinner flanges, will allow satisfactory performance for all cases. The use of a single rib at the web level is not recommended because of the potential for cracking of the weld connecting the rib to the beam.

Much experimental work has been performed on connections with cover plates, the alternative illustrated in the bottom left sketch of Figure 12. The most widely used configuration employed a wide rectangular bottom cover plate to which the beam bottom flange was fillet welded, and a tapered top cover plate which was fillet welded to the beam top flange. The majority of the tests were successful, but some failed prematurely at the welds connecting the flange and cover plate to the column or at the fillet weld connecting the beam bottom flange to the cover plate. The behavior depends strongly on the quality of the welds and on the through-thickness properties of the column flange material. This alternative is cost effective, but it remains to be seen whether it provides the reliability desirable for structural safety.

Of much promise, but not without concerns, is the alternative shown at the bottom right of Figure 12 . Reducing the beam cross section by removing parts of the beam flanges appears to be a safe and cost effective way of relocating the plastic hinge in the beam and reducing the stress level at the connection. In many cases this can be done without increasing the beam cross section because stiffness rather than strength considerations often control the beam size. The added advantage is that the reduced beam bending strength will reduce the maximum moment that can develop in the column, which safeguards against story mechanisms caused by strong beams and weak columns. But it must be considered that the floor slab contributes to the beam strength and the strength reduction may only be partially realized if the slab contribution is large. There are different ways to remove parts of the beam flanges. The outer portions of the beam flanges could be removed, resulting in a dog-bone shaped flange with appropriate curvatures to avoid stress concentrations. It was also suggested to drill a series of holes in the beam flanges. It is difficult to see how stress concentrations can be avoided in the latter case.

There are other alternatives to the standard welded connection that deserve consideration. Spliced connections have been suggested in which either splice plates are welded to the column flange or $T$-sections are bolted to the column flange, and forces are transferred from the beam flanges to the plates by means of high strength bolts in slotted holes. A bronze shim in the shear transfer plane provides for a controlled friction force, which limits the amount of force than can be transferred to the column and acts also as an energy dissipation device. Two experiments with promising results have been performed on this type of connection.

Another alternative is the use of side-plated connections in which the beam flange forces are transferred through welds first to horizontal plates and then to vertical side plates outside the column flanges, and back into the column through horizontal stiffeners welded to the column flanges and web. Several experiments with promising results have been performed on this type of connection.

All of these alternatives have their advantages and disadvantages. But there is enough evidence to state that connections that perform much better than the standard welded connections can be built. There are, however, several concerns that may apply to some or all of the discussed alternatives, and must be brought to the attention of the users.

Moving the beam plastic hinge away from the column face has several consequences on structural behavior. The column flange will no longer provide lateral support to the beam at the location of highest inelastic deformations. Plastification will occur in a region in which the beam bottom flange is laterally unsupported. Thus, lateral torsional buckling may be of concern and additional lateral bracing may have to be provided.

Strengthening the beam at the connection will increase the maximum moment that can be transferred to the joint panel zone and the columns above and below the joint. Let us consider the column issue first. The increased maximum moment in the beam may cause plastic hinging in the columns. This event is much more likely to occur than is predicted by standard procedures. When the plastic rotation demands in the beam are high, the moment capacity of the unreinforced beam may be twice as high as predicted from nominal properties. Disregarding cyclic hardening, which is largely a consequence of plastic hinging, the moment capacity of the column is only about $20 \%$ higher than predicted from nominal properties since 
the mean strength of A572 steel is only $15 \%$ to $20 \%$ higher than the nominal value [8]. In addition, it must be considered that the floor slab may increase the beam strength by a significant amount. Thus, even without beam strengthening the likelihood of plastic hinging in the column may be high. Strengthening of the beam at the connection adds to this likelihood. Plastic hinging in columns may lead to undesirable story mechanisms and may also void the beneficial effect the connection reinforcement is trying to achieve. Tensile yielding in the column flange at a welded beam flange connection may invite fracture across the column flange, which was a much observed local failure mode in the Northridge earthquake.

Increasing the maximum moment in the beam implies that larger shear forces have to be transferred through the joint panel zones (unless the lever. arm between the tension and compression force resultant is increased also). In present designs it is already likely that at interior joints the panel zone will yield in shear before beams attain their plastic moment capacity. Strengthening of beams at connections may add to this likelihood. When joint panel zones have to undergo large plastic shear deformations, which will occur if beams and column remain elastic, the performance of the connection may be greatly affected by panel zone deformations and connection configurations that are based on plastic hinging in beams may be inappropriate.

These issues were brought up to illustrate that connection behavior is not necessarily controlled by the moment and shear in the beam only. All three types of elements existing at the joint, i.e., beams, columns, and the joint panel zone, have an effect on the performance of the connection.

Alternatives to welded connections should be given consideration. Bolted connections are used widely in the U.S. in regions of lower seismicity. Their drawback is that relative rotations will occur between beam ends and columns, which reduced the lateral stiffness. However, there are bolted connection types in which this relative rotation is small. Using stiff bolted connections in many places can accomplish the same as using welded connections in a few places. Clearly, the ductility of bolted connections must be established to the extent that it can be quantified and is found to be sufficient for the level of deformations expected in highly seismic regions.

\section{PERFORMANCE OF MRF STRUCTURES WITH FRACTURED CONNECTIONS}

At this time there are only few certainties about issues and problems caused by fractured connections. One is that a fractured connection constitutes a local failure state that has always undesirable consequences, and the other is that fracture at a few beam-to column flange weld does not necessarily bring a structure much closer to collapse in severe earthquakes. Both points need elaboration.

Let us first consider one connection only. Fracture of one weld (top or bottom of connection) or both welds (top and bottom) will always reduce the lateral strength, stiffness, and energy dissipation capacity of the structure, as well as the gravity load resistance. Alone the reduction in gravity load resistance reduces the safety factor of the structure, by definition. This reduction may be marginal unless fracture extends into the shear $\mathrm{tab}$, in which case the safety factor will be greatly reduced particularly if the shear connection fails. Even in this case some shear transfer can be mobilized through the shear resistance of the slab. The reduction in lateral strength and stiffness will increase lateral displacements under earthquake (and wind) loading, which will adversely affect the serviceability behavior (drift and damage control) and is likely to reduce safety against incremental collapse. To what extent it affects collapse safety depends on the type of local failure, on system behavior, and on the characteristics of the ground motion.

The following discussion tries to raise awareness of consequences of connection failures, but does not pass judgment on the severity of consequences. At this time the information does not exist to pass such judgment.

Except for very unusual earthquakes, a loss in strength, stiffness, and energy dissipation capacity will lead to an increase in displacements. Larger displacements and smaller strength will lead to larger P-delta effects, which will further amplify the displacements. The amount of displacement increase depends on the relative number of fractured versus sound connections and on the frequency characteristics of the ground motion. Larger displacements will amplify the energy dissipation demands on beams (or columns) around sound connections. These elements have limited energy dissipation capacities and may deteriorate in strength and stiffness if the demands become too large. This may increase displacements further. Moreover, the larger demands on the elements may cause more fractures at connections. In addition, a decrease in stiffness at the connection will reduce the end restraints at the columns, which increases the susceptibility to buckling. It is conceivable that the accumulation of all these consequences will lead to incremental collapse of the structure. Only extensive in depths studies will show how likely (or unlikely) such a collapse is.

The severity of the consequences depends on many considerations, some of which are enumerated next.

- Perhaps foremost the total number of moment connections and the relative number of fractured to sound connections. The larger the number of moment connections per floor, the better off the structure is.

- The relative importance of gravity loads compared to lateral stiffness and strength. P-delta effects are proportional to $P \Delta / h \quad(P=$ gravity load on structure, $\Delta=$ lateral displacement, $h=$ story height) and, in the inelastic range, increase significantly for structures with low strength (dynamic P-delta effect).

- Energy dissipation capacity of beams, columns, and joint panel zones. Elements away from fractured connections are called upon to dissipate more energy through inelastic deformations.

- The type of mechanism that develops in the structure. Structures with story mechanisms will experience more severe consequences than structures in which inelastic deformations are distributed over the height.

- The strength and stiffness degradation characteristics of the fractured connections.

- The contribution of the floor slab to the strength and stiffness characteristics of the connections.

- The type of local failure at the connections. Fracture that reduces the strength of the column (the frequently observed fracture across column flanges and sometimes even column webs) may have much more severe consequences than fractures that reduce the moment transfer from beams to columns.

- The frequency characteristics of the ground motion. As stiffness is lost, the effective period of the structure increases. Considering smooth spectra, an increase in period 
leads to an increase in displacements, a decrease in strength demands, and a decrease in energy dissipation demands. What smooth spectra do not show is that energy dissipation demands decrease at a slower rate than strength demands. Actual ground motions, particularly those in soft soils, may have very different characteristics than those reflected in smooth spectra. It is easily possible that period lengthening brings the structure into a spectral range in which strength and energy dissipation demands increase rather than decrease.

This brief discussion is intended to make it clear that there are no simple answers to the question of consequences of connection fractures. The consequences can only be addressed in the context of system behavior. It also needs to be considered that seismic demands, element capacities (in particular the connection strength and deformation capacities), and system capacities are associated with large uncertainties. Thus, a realistic safety evaluation needs to be reliability based, with due consideration given to the uncertainties inherent in demands and capacities and to the consequences of connection fractures on structural safety. This necessitates experimental work to assess the uncertainties in capacities and to develop better models for the hysteretic characteristics of fractured connections. It also necessitates analytical work to develop computer programs that permit realistic and efficient representations of post-fracture behavior, and foremost it necessitates the development of a systematic approach to the safety evaluation of buildings with MRF structural systems.

It is fortunate that our present methods for designing MRF structures and predicting their behavior are based on models that ignore important contributions to strength and stiffness. Foremost are the contributions of floor slabs and of so-called simple shear connections, of which there are usually many in present MRF systems. These simple connections, which in composite floor construction act together with floor slabs, can develop significant strength. At this time the problem is that their stiffness characteristics are difficult to predict and depend strongly on the tightness of the bolts in the shear connection. There is no doubt, however, that these connections contribute significantly to the collapse safety of MRF structures.

\section{CONCLUSIONS}

The Northridge earthquake has subjected a large number of steel structures to a severe seismic test. A few problems were exposed in braced frame structures; these problems can be solved through relatively simple modifications in seismic design and detailing requirements. The problems exposed in welded connections of moment resisting frame structures have no simple solution. By now there is little doubt that the standard welded beam-to-column connection, which has been used in most steel MRF structures built during the last 35 years in highly seismic regions of the U.S., does not provide the reliable performance desired for seismic safety.

Solutions to the welded connection problems pose a challenge to the engineering community. Many preliminary recommendations that will lead to great improvements in connection performance can be made already. Definite and comprehensive solutions have to be developed through collaboration between researchers, practicing engineers, metallurgists, and welding experts. There is no doubt that such solutions can and will be developed so that advantage can be taken also in the future of steel MRFs, whose many excellent performance characteristics make them desirable structural systems in seismic regions.

There is a need, however, to improve system behavior by better detailing around connections. This can be achieved in several ways. If welded connections are used, the quality of welding must be improved and the stress level around the welds must be kept at a safe level. This requires consideration of the expected rather than nominal strength of the elements (including cyclic hardening), and the development of configurations in which overstressing of welds in severe earthquakes is avoided. Moving beam plastic hinges away from the welded regions is a desirable option. When this is done by reinforcing the connection region, moments that are larger than the strength of the unreinforced beam will be transferred to the joint panel zone and the columns. The effects of these larger moments on panel zone and column behavior as well as on system behavior (possible development of undesirable story mechanisms) need to be evaluated. Alternatively, stresses at weldments can be kept at a safe level by reducing the beam cross section away from the connection. More consideration should be given to the use of bolted connections as alternatives to welded connections.

An overriding consideration for structural safety is redundancy. This has been known for a long time, but has been difficult to quantify in the past. The recent incidences of connection failures make it possible now to quantify the benefit of redundancy from a system's perspective. Reliability analysis will show this benefit explicitly in the future. Until methods for such an analysis will be common knowledge, the design emphasis should be to provide as much redundancy as is economically feasible. Designers should be encouraged to avoid minimizing the number of moment resisting connections and to provide moment connections in several frames and not just at the perimeter of a structure.

\section{REFERENCES}

1 American Welding Society. 1994. Structural welding code steel. AWS D1.1-94.

2 Bertero, V V, Anderson, J C, and Krawinkler, H 1994. Performance of steel building structures during the Northridge earthquake. Report No. UCB/EERC-94/09, Earthquake Engineering Research Center, University of California at Berkeley.

3 Engelhardt, M D and Sabol, T A 1994. Testing of welded steel moment connections in response to the Northridge earthquake. Progress Report to the AISC Advisory Subcommittee on Special Moment Resisting Frame Research.

4 Krawinkler, H 1978. Shear design of steel frame joints. Engineering Journal, AISC, Vol. 15, No. 3.

5 Krawinkler, $\mathrm{H}$ et al. 1983. Recommendations for experimental studies on the seismic behavior of steel components and materials. John A. Blume Earthquake Engineering Center, Report No. 61, Department of Civil Engineering, Stanford University.

6 Roeder, C W 1989. Seismic behavior of concentrically braced frames. Journal of Structural Engineering, ASCE, Vol. 115, No. 8, pp. 1837-1856. 
7 SAC 1995. Interim Guideline No. 1. SAC Joint Venture Partnership.

8 SSPC 1994. Statistical analysis of tensile data for wide flange structural shapes. Steel Shape Producers Council.

9 Uang, C-M and Bertero, V V 1986. Earthquake simulation tests and associated studies of a 0.3 scale model of a sixstory concentrically braced steel structure. Report No. UCB/EERC-86/10, EERC, University of California at Berkeley.

10 Uang, C-M and Latham, C T 1995. Cyclic testing of fullscale MNH-SMRF moment connections. Structural Systems Research, University of California, San Diego.

11 Youssef, N F G, Bonowitz, D, and Gross, J L 1995. A survey of steel moment-resisting frame buildings affected by the 1994 Northridge earthquake. NISTIR 5625, National Institute of Standards and Technology, Gaithersburg, Maryland. 